\section{Utility of medical simulation in neurovascular critical care education}

Sandra Mass-Ramírez, $\mathrm{MS}^{1}$; Hernán Vergara-Burgos, $\mathrm{MS}^{1}$; Carmen Sierra-Ochoa, MS ; I Ivan David Lozada-Martinez, MS ${ }^{1,2,3}$; Luis Rafael Moscote-Salazar, MD, PhD(c) ${ }^{1,2,3}$; Tariq Janjua, MD; Md Moshiur Rahman, MD ${ }^{5}$; Sabrina Rahman, BSc, MPH ${ }^{6}$; Yelson Alejandro Picón-Jaimes, MD, MSc ${ }^{7}$

'Medical and Surgical Research Center, School of Medicine, University of Cartagena, Cartagena, Colombia

${ }^{2}$ Colombian Clinical Research Group in Neurocritical Care, School of Medicine, University of Cartagena, Cartagena, Colombia

${ }^{3}$ Latin American Council of Neurocritical Care, Cartagena, Colombia

${ }^{4}$ Department of Intensive Care, Regions Hospital, Saint Paul, MN, USA

${ }^{5}$ Department of Neurosurgery, Holy Family Red Crescent Medical College, Dhaka, Bangladesh

${ }^{6}$ Department of Public Health, Independent University-Bangladesh, Dhaka, Bangladesh

${ }^{7}$ Medical and Surgical Research Center, Valencian International University, Santiago de Chile, Chile

\section{REVIEW ARTICLE}

Received: April 1, 2021

Revised: April 23, 2021

Accepted: May 9, 2021

Corresponding Author: Ivan David Lozada-Martinez, MS Medical and Surgical Research Center, School of Medicine, University of Cartagena, Cra 50, Cartagena 24120, Colombia

Tel: +57-31-5779-9823

Fax: +57-31-5779-9823

E-mail: ilozadam@unicartagena.edu.co

Simulation has shown good results in medical scenarios in which the patient's problem can be solved by following protocols previously established in clinical practice guidelines. Therefore, the implementation of simulation programs in neurocritical care improves the outcomes of patients at clinical centers because a properly trained professional will be able to provide the most effective care in the shortest time possible, safeguarding the patient's life. Some learning and simulation models that can be included in medical education to improve neurocritical vascular care include task trainers, full-body mannequins, standardized patients, and computer-based simulation. Specifically, medical simulation in academic training programs in health sciences has a great impact on the development of specific skills, which could potentially reduce medical-legal and economic issues, improve care, and result in the management of clinical events. Simulation is established as an essential educational tool, allowing the instruction of knowledge from an interactive perspective and offering a broader vision when it comes to medical practice. The objective of this article is to present evidence related to the usefulness and impact of medical simulation in neurovascular critical care education.

Keywords: Simulation training; Computer simulation; Medical education; Cerebrovascular disorders; Central nervous system diseases; Health education

\section{INTRODUCTION}

In the process of medical education, there are three essential principles of knowledge that trainees must learn: know, know how, and know to be [1]. These pillars allow the development of communication skills, professional attitude, medical judgment, clinical dexterity when performing a physical examination and medical history, and technical capacity when performing a diagnostic or therapeutic procedure, orientating them towards the resolution of the patient's condition $[1,2]$. The acquisition and refinement of these skills comprise the core of what medical education should represent [3]. The integration, specifically of knowing how medi- 
cal training allows the learner to acquire both rational and practical abilities, including the development of clinical reasoning and the capacity to formulate an integrated action plan for the management of the patient, an archetype to clinical practice. This is essential to promote the quality of healthcare professionals and the improvement of their techniques [2].

Currently, many trainees point to learning gaps in their educational processes, particularly in the practical component [1]. In neurology, this problem is more common, translating into the fear of facing cases involving neurocritical medicine. This is attributable to both the diagnostic and therapeutic challenges that they imply and the level of knowledge that one must possess to treat them [4]. Similarly, fewer and fewer people have been interested in neurosurgical and neurointensive specialties. This is a growing concern and a problem for the health system since many patients attend to the emergency room with acute neurological pathologies but the supply of medically trained personnel is limited [4]. Therefore, education models that consolidate the necessary knowledge for both students and medical professionals should be implemented to increase their confidence, security, and competence when managing cases in neurocritical care.

A solution to this issue is the incorporation of simulation-based education, which has been very well received in the educational field since its inclusion in aviation for pilot training and in medicine in 1960 through the introduction of the Rescue Annie dummy to train people in cardiopulmonary resuscitation [4]. Simulation provides an ideal, effective, and safe learning environment for medical learners when acquiring clinical knowledge and skills [5]. Hence, the objective of this review is to provide evidence related to the utility of medical simulation in neurocritical care, especially in neurovascular care.

\section{MEDICAL SIMULATION}

Simulation is a method used to recreate a situation without having to participate in a real event, and its main objective is to optimize the learning process and develop skills to improve professional performance [6-9]. This model is called experience-based learning because it offers a common practice scenario, followed by feedback and analysis of what has been learned and what could improve the results $[10,11]$. Although encounters with patients are an important component for learning in medicine, simulation grants previous exposure in different complex circumstances that may pose a risk to the patient, providing the trainee with a safe environment to develop their capability, acquire skills, and reflect on mistakes without putting their professional reliability at risk $[6,12,13]$. Furthermore, it can be used as a complement to experi- ences seen in patient care, providing educational opportunities that are not available in real events $[6,14]$.

Learners are partially responsible for their education. To be able to access simulation-based learning, the apprentice must first acquire prior theoretical notions about basic sciences to confront clinical scenarios [15]. In addition, the habit obtained when treating the patient will accredit the trainee to act efficiently, professionally, and empathically, that is, to treat the patient satisfactorily $[16,17]$. The integration of the three aforementioned principles allows educating individuals who are capable of dealing with clinical problems with cleverness. When learners are competent, they are more confident with their abilities and proficient in correctly executing procedures because their knowledge has solid foundations $[3,18]$.

Moreover, a responsible and well-trained instructor is in charge of participating in the improvement of the students' capacities by evaluating their performance in an impartial manner, providing information, pointing out errors, and offering support and guidance during the debriefing. All of which focus on the abilities of the evaluated person. The instructor also leads the discussion where it is necessary to fulfill the learning objectives $[19,20]$. Ahmed et al. [21] conducted a cross-sectional observational study to evaluate the point of view of medical professors on the integration of simulation-based medical education and found that the majority of respondents recognized that simulation is an effective tool that can benefit teaching outcomes. Furthermore, its inclusion in the curriculum is indispensable and should not be conceived as an isolated activity. Roze et al. [22] proposed a simulation exercise in which trainees represented a patient suffering a neurological syndrome, and the attending physician supervised by a tutor. Student motivation, learning, topic understanding, communication skills, and learner confidence were found to be considerably improved $[22,23]$.

As mentioned earlier, one of the main features of simulation is feedback. In fact, it is one of the most studied and has the most evidence related to effective learning based on this method of education $[14,24,25]$. van de ridder et al. [26] described feedback in clinical education as a "specific information about the comparison between the performance of an apprentice and a standard, given with the intention of refining the management of the apprentice." Feedback ensures that the teaching objectives are met and provides a post-event reflection process [14]. In addition, debriefing is proposed as an exchange or discussion following the medical simulation, allowing learners to receive feedback, understand their actions, and better the results of their intervention. This helps incorporate new information into previous knowledge $[19,27]$. This method also enhances technical and behavioral skills [19]. 
Other characteristics of simulators that lead to proficient education include repetitive practice, range of levels of difficulty, diverse learning strategies, controlled environments, and individualized learning [25].

Over time, various types of simulations have been created and implemented to satisfy certain purposes, each having its own characteristics and level of complexity (Table 1) [28]. (1) Part task trainers: these consist of three-dimensional (3D) anatomical models whose objective is to represent a specific part of the human body and to educate as similar to reality as possible. With these structures, deliberate practice of regularly used procedures in the clinical setting for the acquisition of skills can be achieved [24,29]. (2) Full-body mannequins: 3D anatomical models with sizes and physiognomies very similar to a real human body. The complexity of these structures can vary depending on the age of the patient represented, ability to offer physiological responses, systemic reactions, and even present neurological signs, which can be controlled by electronic devices managed by an operator in real time or through responses programmed directly into the mannequin [29]. This type of simulator allows the development of teamwork skills, handling critical events, and offers a method for evaluation. Studies have shown that this type of simulation is helpful for learning in critical care [24]. (3) Standardized patients: this group consists of actors with previous training in the simulation of specific clinical situations. Their participation allows the trainee to obtain a real experience in their practical exercise. They are important in the training of medical learners for the acquisition of competencies, such as empathy and communication $[24,29]$. Professionals, amateurs, and sometimes "real" patients, called expert patients, perform this role [30]. (4) Computer-based simulation: it consists of virtual representations of specific medical situations whose objective is to develop skills in the trainee. Their level of complexity ranges from a basic computer program to virtual reality programs that permit interaction with patients [29]. This option offers the opportunity to recreate scenarios that cannot be carried out with other types of simulation, such as disaster scenarios or terrorist attacks [24]. (5) Hybrid simulators: the types of simulation previously mentioned can be combined and carried out simultaneously in a practical exercise, with the goal of enhancing the academic value of the activity and increasing the learning process for the apprentice $[24,29]$.

\section{SIMULATION IN NEUROCRITICAL CARE}

Neurological diseases account for a large percentage of admissions to the emergency department. Consequently, the clinician who is going to perform the evaluation and management of the patient must do so optimally and quickly $[31,32]$. The care of patients with acute neurological disorders requires a set of techniques, skills, and aptitudes on the part of healthcare personnel because the severity of these disorders are at risk for high rates of mortality and morbidity, such as compromised motor function and disability [33].

Many physicians, residents, and students feel anxious when dealing with neurological patients, which may be related to the lack of knowledge and little contact with these specific groups of patients during their training [34]. These fears and insecurities can be observed when health personnel are unsure how to act when facing these types of situations, which has a negative impact on the health of the patient, given that the first hours in the management of neurocritical events are crucial. For this reason, proper neuroscience education is essential to avoid fatal outcomes [33-36].

Traditionally, teaching neurologic emergencies is often transmitted through lectures, assigned readings, self-study modules, or demonstration of important findings in patients with neurological diseases [10]. For instance, during their clinical practice rotations, medical learners know the basic principles of the neurological ex-

Table 1. Summary of the simulation modalities currently implemented in the learning process in healthcare education

\begin{tabular}{|c|c|c|}
\hline Simulation modality & Characteristics & Example \\
\hline Part task trainers & $\begin{array}{l}\text { Three-dimensional anatomical structures of specific } \\
\text { parts of the human body that allow the practice of } \\
\text { tasks and development of skills }\end{array}$ & $\begin{array}{l}\text { Synthetic leather pads to practice sutures; structures } \\
\text { for practicing airway management/intubation }\end{array}$ \\
\hline Full-body mannequins & $\begin{array}{l}\text { Three-dimensional anatomical model of the human body } \\
\text { with the ability to respond to specific situations }\end{array}$ & $\begin{array}{l}\text { The SimMan 3G, HAL S3201, the Human Patient Simu- } \\
\text { lator }\end{array}$ \\
\hline Standardized patients & Actors with training in specific clinical situations & Trained actors, volunteers \\
\hline Computer-based simulation & $\begin{array}{l}\text { Computer programs allow the acquisition of medical } \\
\text { knowledge and the practice of skills. }\end{array}$ & $\begin{array}{l}\text { The Neurological Exam Rehearsal Virtual Environment, } \\
\text { NewroSim }\end{array}$ \\
\hline Hybrid simulators & Practice various types of simulation in the same scenario & $\begin{array}{l}\text { Standardized patient wound simulator which can } \\
\text { project emotions such as fear, anger, anxiety, this will } \\
\text { reinforce practical wound management skills, com- } \\
\text { munication skills, and learning to work under pres- } \\
\text { sure. }\end{array}$ \\
\hline
\end{tabular}


amination and its possible variations in patients with an acute event. However, this knowledge is acquired by consulting the books provided by the teacher, practicing with colleagues, and checking on patients with sequels of a previous episode. As such, they rarely confront the real situation, which can generate gaps and impede proper professional performance. In the same way, many learners report feeling incapable and uncomfortable in performing neurological examinations as a consequence of the lack of understanding of basic sciences, which decreases their efficiency and motivation. This also subsequently limits their clinical expertise in an environment where they might be in charge of providing the initial management in the future $[35,37,38]$.

Several studies $[2,3,5,6,9,13,39]$ have shown that "people give more significance to the knowledge they obtain from experience than to those they acquire passively." Therefore, it is necessary to implement tools that mediate the acquisition of knowledge in an active manner; in this case, instructing the trainee in a pragmatic way during their learning process [39]. However, there are situations where there is little or no opportunity to practice, such as in neurocritical events, which are characterized by the rapid deterioration of patients and the need for rapid and effective intervention by a specialized team [39]. Evidence supporting this includes the Neurocritical Care Education During Residency: Opinions (NEURON) study, which concluded that a significant number of neurology residents were concerned about training in neurocritical care, expressing that education within the neurocritical care unit is very restricted and should change to benefit the student's experience [40]. For this reason, simulation is an essential tool to recreate these types of scenarios as similar to reality as possible.

Before being exposed to real situations, the inclusion of these simulated spaces in neurocritical care offers the opportunity to learn how to communicate effectively with a team during an emergency, make quick decisions, correctly identify patients with critical neurological conditions, and implement appropriate treatment algorithms that help develop the reliability of the staff and their expertise in patient management $[8,10,41]$. Similarly, by incorporating simulations, the learner can experience failure and recognize the limits of their capacities, which results in the reduc- tion of errors and better care to the patient and their loved ones $[6,42]$.

\section{SIMULATION IN NEUROVASCULAR CRITICAL CARE}

The most frequently reported cause of neurological emergencies, and consequently, the main reason for consultation faced by neurologists on call is acute cerebrovascular disease [32,43]. According to the World Health Organization, stroke is the second leading cause of death worldwide, accounting for approximately $11 \%$ of deaths in 2019 [44,45]. Additionally, it is the leading cause of acquired physical disability in adults, the leading cause of epilepsy in older people, and the second most common cause of late-onset dementia. Likewise, cerebrovascular accidents have been ranked as the first or second most common cause of death in South American countries, which was aggravated by the poor system of care in neuroemergencies [46].

Based on the previous information, the implementation of simulation programs in neurovascular critical care can increase the life expectancy of patients who arrive at hospital centers due to stroke and other neurological conditions as it will provide them with the opportunity of better care in the hands of trained personnel, who are not necessarily specialists, for these situations. In addition, it also promotes the process of learning and education (Table 2) [46-49].

In London, simulated education has been practiced for several years and has been useful in professional stroke training and in establishing the acute stroke unit model. It has also been utilized to train first response personnel to perform thrombolysis [8]. In stroke, there is an important correlation between the time of onset of symptoms to the time of recanalization of the affected blood vessel. Simulation is used in this case as an educational technique to ensure prompt attention and assessment. Tahtali et al. [50] proposed to train the subjects based on the data collected regarding the care provided to the patient, over conferences given to the health workers and suggested that a well-structured team generally consists of a neurologist, radiologist, resident, and nurse, who

Table 2. Advantages of implementing medical simulation in neurovascular care education [46-49]

\author{
Advantage of simulation in neurovascular care \\ The "know-how" of the three essential principles of knowledge in medical education is put into practice. \\ Provides an effective and safe learning environment in the acquisition of knowledge in neurovascular critical care \\ Allows the acquisition of clinical reasoning skills \\ Improves trainees' confidence, security, and skill in the neurocritical care approach \\ Reduces trainees' insecurity when facing neurocritical situations \\ Allows the development of teamwork skills during critical events
}


coordinate strategies to reduce the patient waiting time for treatment.

In addition, Ospel et al. [51] conducted an international multidisciplinary survey, with the intention of determining the point of view of neurointerventionalists about the errors regularly committed in the endovascular treatment of unruptured intracranial aneurysms. They found that the faults that most regularly caused complications were related to technical execution and suggested that these faults can be prevented by strengthening the abilities of medical personnel through training in simulation settings. As a result, it would be ideal for simulation to be widely available to physicians and to become a part of the equipment in intervention centers, similar to surgical specialties that use this learning modality permanently in their academic training program [51-53].

To meet the requirements for appropriate therapy in cases of neurovascular events, educational programs and hospital centers resort to strategies that guarantee a better level of qualification, surgical success, and efficient ways to pass on knowledge to their staff. In an attempt to promote education and training in neurocritical care, the Neurocritical Care Society developed an emergency neurological life support course, which teaches health professionals the correct management of patients during the first hours of a neurological urgency [54]. The course provides a series of guidelines and protocols for the care of patients with acute neurological conditions, including acute ischemic stroke and intracerebral and subarachnoid hemorrhage, which are some of the main cerebrovascular pathologies [54].

\section{NEUROVASCULAR SIMULATION MODALITIES}

Other learning and simulation modalities that can be included in different medical schools as a strengthening method in the area of vascular neurocritical care are as follows.

\section{Task trainers}

Physical simulators are necessary for the apprentice to acquire practical experience and be able to face the critical situations of patients with neurovascular conditions. An example of this is the creation of simulated models of cerebral aneurysms that can help neurology residents and neurosurgeons gain a solid foundation of knowledge and well-developed surgical skills for the treatment of this condition [55].

Wurm et al. [56] used stereolithography and 3D printing to design aneurysms with surrounding blood vessels and the neurocranium to perform clipping surgeries. They concluded that $3 \mathrm{D}$ printing is the most promising technique for creating neurovascular structures [56]. Benet et al. [57] reported the fabrication of a customized aneurysm using a $3 \mathrm{D}$ printer for use in a human cadaver to facilitate training in the approach of complex surgical cases and interventions. Torres and De Luccia [58] developed a simulation system for endovascular aneurysm repair using a 3D printer, which improved the performance of vascular surgery residents by reducing fluoroscopy and procedure time.

Recently, in order to help train neurosurgeons in the management of aneurysms and complications during surgery, Chen et al. [59] created a physical simulator that realistically imitated the brain stem, brain lobes, cerebral arteries, and the circle of Willis, with aneurysms designed to occur in places where they are most likely to appear. This has been evaluated and supported by several studies [60-62].

Furthermore, Joseph et al. [63] designed a physical simulator based on a 3D printed model of the patient's skull, brain, and specific arteries that is capable of imitating the experience of intracranial aneurysm microsurgery. Based on the participants' evaluations, the vast majority ( $84 \%$ ) indicated that the use of the simulator was a better alternative than conventional neurosurgical training methods, considering that this type of surgery was very limited at the time of neurosurgical residency. Therefore, simulation allows the acquisition of experience and encounter with this type of situation where practice is very scarce due to its critical component.

Other goals obtained from neurovascular simulation include improving the understanding of cerebral vascular anatomy in three dimensions, developing a detailed understanding of the neurosurgeon's view of aneurysm position and accessibility, and familiarizing the neurosurgeon with the methods and instruments used during surgery [64]. Additionally, the neurosurgeon benefits from simulation in aneurysm repair for training in both open vascular surgery (surgical clipping) and endovascular treatment [64].

Cranioencephalic trauma simulators have also been designed to teach skills necessary for the management of traumatic brain injuries, where specific pathologies, such as subdural and epidural hematomas, can be programmed [65]. Lobel et al. [65] developed a neurosurgical simulation curriculum that was presented at the 2012 Congress of Neurological Surgeons. Within this curriculum, a trauma model was designed to teach traumatic brain injury management skills and, subsequently, the residents' participation in this module. Improvements in practical knowledge were observed after the training and coaching $[65,66]$.

\section{Full-body mannequins}

Musacchio et al. [67] incorporated a human patient simulator by 
Medical Education Technology, Inc. (METI, Sarasota, FL, USA), a multifunctional simulator that displays parameters such as blood pressure, oxygenation, cerebral perfusion, pulse, and intracranial pressure. This can also be used to perform procedures such as drug administration, intubation, mechanical ventilation, or cardiopulmonary resuscitation. In addition, it reacts to reflexes, maneuvers, and interventions performed by the examinee. The authors intended to construct scenarios capable of evaluating the response of residents and learners to the management of neurocritical pathologies, such as spinal shock, cranioencephalic trauma, cerebral vasospasm, hemorrhage, and cerebral herniation. The mannequin communicated with the trainee through a speaker that was controlled by the supervisor. Moreover, the learners underwent pre-exercise and post-exercise evaluations and a satisfaction survey. Afterward, the obtained knowledge was measured, and a substantial improvement was evidenced in most of the participants.

\section{Standardized patients}

In a study in 2011, Mehta et al. [68] added a practical component based on acute stroke simulation to the academic program for first-year neurology studentsn. Standardized patients were used for this exercise, where the actress was a nurse trained by a vascular neurology specialist, who instructed her what signs she should manifest in order to simulate stroke and make the simulation exercise as close as possible to a real case.

During the exercise, the residents were supervised by a specialist, and a report of their performance was given to them at the end of the procedure. Many residents agreed that one of the benefits of the simulation was that they were able to recognize their faults and thus correct them, allowing them to have more confidence in themselves when interacting with a real patient [68]. The results of this study allowed a notable improvement in the performance of the residents, which reduced the time of administration of treatment in stroke patients by approximately 9 minutes [68]. In stroke, every second that passes is vital for the maintenance of neuronal integrity. As such, it is of utmost importance to shorten the breach of time from the patient's arrival to the institution until the implementation of treatment to achieve the best results $[69,70]$.

\section{Computer-based simulation}

With advances in technology, virtual spaces have been designed to allow learners to access the information that they require for their studies from their computers [71]. E-learning refers to the use of the Internet or information technologies for educational activities, offering accessibility and flexibility to control their own learning
[72]. An example of this is the e-brain platform, which has more than 600 interactive and multimedia lessons, webinars, virtual case reports, and practice exams to support professional development $[72,73]$.

Likewise, virtual reality programs have been increasingly used in simulation, leading to an immersive learning environment and advancements in the way vascular diseases are diagnosed and treated [71,74-75]. NeuroTouch is a virtual reality model through which the representation of predetermined clinical scenarios is made possible. It was developed to teach skills on the implementation of specific clinical situations, such as resection of brain tumors, restoration of hemostasis, and ultrasonic aspiration [76]. It also allows for the evaluation of several parameters in the sample case, such as the time spent in the procedure, volume of blood lost during the procedure, and the degree of force that is applied to the tissue [76]. With the correct use of this model, trainees will be able to improve their skills and their ability to quickly and efficiently visualize vascular structures and increase their confidence in the procedures, which lead to reduced complications [74].

Similarly, a virtual neurological model known as NewroSim has been developed, which has the capacity to simulate the main cerebrovascular alterations present in various pathological conditions, such as stenosis of the intracranial and extracranial arteries [77]. This equipment makes it possible to reproduce the hemodynamics of cerebral vessels and observe cerebral blood flow velocities using transcranial Doppler $[24,78]$. The use of NewroSim in the practice of neurological scenarios is of great help to learners as it allows them to observe the changes in cerebral perfusion and their direct impact on the neurological disorder of the patient $[77,78]$.

On the other hand, given the increasing number of endovascular interventions for stroke treatment, simulation can play an important role in gaining experience, particularly for beginners, because any complication in this type of procedure can have serious consequences [79]. Kreiser et al. [79] found that the use of an angiography simulator allowed medical students and residents to learn about the principles of performing angiographic examinations and the necessary steps in specific interventions, such as carotid stent placement or aneurysm coiling. Likewise, Spiotta et al. [80] studied the usefulness of simulated diagnostic cerebral angiography among neurosurgical residents and fellows using an endovascular biplane angiography simulator and demonstrated that simulation facilitated the acquisition of technical angiography skills. Currently, other endovascular simulators, such as Procedicus VIST and ANGIO Mentor, allow learners to practice without the risk of harm to the patient, improving performance in a stressfree environment. When errors would occur, the simulators would generate feedback, thus facilitating learning [81]. 
Finally, treatment of ischemic stroke usually consists of the administration of recombinant tissue-type plasminogen activator within 4 hours of symptom onset, and its combination with mechanical thrombectomy has shown improved outcomes [82]. Simulation through virtual reality enhances learners' experience in performing mechanical thrombectomy through the use of and familiarization with endovascular devices, thrombectomy devices, catheters, and guidewires. This exercise demonstrated that apprentices who participated in simulation activities obtained better results than those who did not $[82,83]$.

\section{LIMITATIONS IN THE USE OF SIMULATION}

There is very limited literature on the expenses incurred in the implementation of simulations in a medical setting [25]. However, the common point in most studies is the high cost, since mannequins, virtual reality simulators, and other types of simulators do not have very accessible prices. In addition, these equipment require adequate personnel for their management and maintenance, which greatly increases the costs of simulation in education [24]. Technological advances come in giant steps, and what today seems to be a great simulation equipment can quickly become obsolete. Therefore, it may not be viable to make this investment [84].

Simulation has shown good results in medical scenarios in which the patient's problem can be solved following protocols previously established in clinical practice guidelines, such as cardiopulmonary resuscitation, a common practice among health professionals [85]. However, in neurological emergencies, the most important thing is to be able to obtain a diagnosis before implementing previously established protocols. The issue is not as simple as one might think, and the solution to that problem depends on the encounter between the physician and the patient [86].

Actors are trained to represent classical patterns of a specific disease. However, in reality, patients may show nonspecific signs. Simulation may not sufficiently teach some skills since the scenario will never be the same as the real one, and no matter how hard one tries, there are certain characteristics that could never be simulated by an actor or a mannequin [86]. Hocker et al. [86] stated in their study that learners will hardly succeed in maximizing their knowledge and skills until they experience dealing with a real patient.

Therefore, although simulation is an important component of knowledge acquisition, it does not replace intimate patient contact because it is a component that ultimately determines problem-solving, decision-making, and communication skills. Hence, it is necessary to complement both simulation and practice in real situations to train competent professionals.

\section{CONCLUSION}

Medical simulation in academic training programs for health sciences has a great impact on the development of specific skills, potentially reducing medical-legal and economic complications and improving care and results in the management of clinical events. Simulation is an essential educational tool that imparts knowledge from an interactive perspective and offers a broader vision in relation to the practice of medicine. In neurocritical care, specifically neurovascular care, the visualization of these environments represents an opportunity to develop rapid and accurate decision making, allowing the maintenance of neuronal integrity and functional capacity of the patient, and ultimately reducing morbidity and mortality.

\section{ARTICLE INFORMATION}

\section{Ethics statement}

Not applicable.

\section{Conflict of interest}

No potential conflict of interest relevant to this article.

\section{ORCID}

Sandra Mass-Ramírez https://orcid.org/0000-0001-9246-108X

Hernán Vergara-Burgos https://orcid.org/0000-0003-1671-7754

Carmen Sierra-Ochoa https://orcid.org/0000-0002-0532-8983

Ivan David Lozada-Martinez https://orcid.org/0000-0002-1960-7334

Luis Rafael Moscote-Salazar https://orcid.org/0000-0002-4180-6962

TariqJanjua $\quad$ https://orcid.org/0000-0001-5852-0090

MdMoshiurRahman https://orcid.org/0000-0002-1183-6829

Sabrina Rahman https://orcid.org/0000-0002-4057-3116

Yelson Alejandro Picón-Jaimes https://orcid.org/0000-0002-7498-5346

\section{Author contributions}

Conceptualization: all authors. Data curation \& Formal analysis: SMR, HVB, CSO, IDLM. Methodology \& Project administration: all authors. Visualization: IDLM, LRMS, TJ, MMR, SR, YAPJ. Writing-original draft, review \& editing: all authors.

\section{REFERENCES}

1. Nousiainen MT, Caverzagie KJ, Ferguson PC, Frank JR; ICBME Collaborators. Implementing competency-based med- 
ical education: what changes in curricular structure and processes are needed? Med Teach 2017;39:594-8.

2. Al-Elq AH. Simulation-based medical teaching and learning. J Family Community Med 2010;17:35-40.

3. Datta R, Upadhyay K, Jaideep C. Simulation and its role in medical education. Med J Armed Forces India 2012;68:167-72.

4. Aebersold M. The history of simulation and its impact on the future. AACN Adv Crit Care 2016;27:56-61.

5. Agha S. Effect of simulation based education for learning in Medical Students: a mixed study method. J Pak Med Assoc 2019;69:545-54.

6. So HY, Chen PP, Wong GK, Chan TT. Simulation in medical education. J R Coll Physicians Edinb 2019;49:52-7.

7. Konakondla S, Fong R, Schirmer CM. Simulation training in neurosurgery: advances in education and practice. Adv Med Educ Pract 2017;8:465-73.

8. Galtrey CM, Styles J, Gosling N, Nirmalananthan N, Pereira AC. Acute neurology simulation training. Pract Neurol 2018; 18:477-84.

9. McGaghie WC, Issenberg SB, Cohen ER, Barsuk JH, Wayne DB. Does simulation- based medical education with deliberate practice yield better results than traditional clinical education? A meta-analytic comparative review of the evidence. Acad Med 2011;86:706-11.

10. Wijdicks EF, Hocker SE. A future for simulation in acute neurology. Semin Neurol 2018;38:465-70.

11. Abatzis VT, Littlewood KE. Debriefing in simulation and beyond. Int Anesthesiol Clin 2015;53:151-62.

12. Hepps JH, Yu CE, Calaman S. Simulation in medical education for the hospitalist: moving beyond the mock code. Pediatr Clin North Am 2019;66:855-66.

13. Mundell WC, Kennedy CC, Szostek JH, Cook DA. Simulation technology for resuscitation training: a systematic review and meta-analysis. Resuscitation 2013;84:1174-83.

14. Motola I, Devine LA, Chung HS, Sullivan JE, Issenberg SB. Simulation in healthcare education: a best evidence practical guide. AMEE Guide No. 82. Med Teach 2013;35:e1511-30.

15. Finnerty EP, Chauvin S, Bonaminio G, Andrews M, Carroll RG, Pangaro LN. Flexner revisited: the role and value of the basic sciences in medical education. Acad Med 2010;85:349-55.

16. Hashim MJ. Patient-centered communication: basic skills. Am Fam Physician 2017;95:29-34.

17. Noordman J, Post B, van Dartel AA, Slits JM, Olde Hartman TC. Training residents in patient-centred communication and empathy: evaluation from patients, observers and residents. BMC Med Educ 2019;19:128.

18. Schrant BL, Archer LL, Long R. Human patient simulation as a teaching tool. Mo Med 2018;115:71-4.

19. Abulebda K, Auerbach M, Limaiem F. Debriefing techniques utilized in medical simulation. Treasure Island, FL: StatPearls Publishing; 2020.

20. Choi W, Dyens O, Chan T, Schijven M, Lajoie S, Mancini ME, et al. Engagement and learning in simulation: recommendations of the Simnovate Engaged Learning Domain Group. BMJ Simul Technol Enhanc Learn 2017;3:S23-32.

21. Ahmed S, Al-Mously N, Al-Senani F, Zafar M, Ahmed M. Medical teachers' perception towards simulation-based medical education: a multicenter study in Saudi Arabia. Med Teach 2016;38 Suppl 1:S37-44.

22. Roze E, Flamand-Roze C, Méneret A, Ruiz M, Le Liepvre H, Duguet A, et al. 'The Move', an innovative simulation-based medical education program using roleplay to teach neurological semiology: students' and teachers' perceptions. Rev Neurol (Paris) 2016;172:289-94.

23. Bosse HM, Nickel M, Huwendiek S, Jünger J, Schultz JH, Nikendei C. Peer role-play and standardised patients in communication training: a comparative study on the student perspective on acceptability, realism, and perceived effect. BMC Med Educ 2010;10:27.

24. Morris NA, Czeisler BM, Sarwal A. Simulation in neurocritical care: past, present, and future. Neurocrit Care 2019;30:522-33.

25. Issenberg SB, McGaghie WC, Petrusa ER, Lee Gordon D, Scalese RJ. Features and uses of high-fidelity medical simulations that lead to effective learning: a BEME systematic review. Med Teach 2005;27:10-28.

26. van de Ridder JM, Stokking KM, McGaghie WC, ten Cate OT. What is feedback in clinical education? Med Educ 2008;42: 189-97.

27. Cheng A, Morse KJ, Rudolph J, Arab AA, Runnacles J, Eppich $W$. Learner-centered debriefing for health care simulation education: lessons for faculty development. Simul Healthc 2016; 11:32-40.

28. Okuda Y, Bryson EO, DeMaria S Jr, Jacobson L, Quinones J, Shen B, et al. The utility of simulation in medical education: what is the evidence? Mt Sinai J Med 2009;76:330-43.

29. Weller JM, Nestel D, Marshall SD, Brooks PM, Conn JJ. Simulation in clinical teaching and learning. Med J Aust 2012;196:594.

30. Verborg S, Cartier I, Berton J, Granry JC. Medical consultation simulations and the question of the actors: simulated or standardized patients. Bull Acad Natl Med 2015;199:1165-72.

31. Langlo NM, Orvik AB, Dale J, Uleberg O, Bjørnsen LP. The acute sick and injured patients: an overview of the emergency department patient population at a Norwegian University Hospital Emergency Department. Eur J Emerg Med 2014;21:175- 
80.

32. Lange MC, Braatz VL, Tomiyoshi C, Nóvak FM, Fernandes AF, Zamproni LN, et al. Neurological diagnoses in the emergency room: differences between younger and older patients. Arq Neuropsiquiatr 2011;69:212-6.

33. Da Silva IR, Gomes JA. Residency Training: the role of neurocritical care in resident education. Neurology 2013;80:e51-3.

34. Tarolli CG, Józefowicz RF. Managing neurophobia: how can we meet the current and future needs of our students? Semin Neurol 2018;38:407-12.

35. Matthias AT, Nagasingha P, Ranasinghe P, Gunatilake SB. Neurophobia among medical students and non-specialist doctors in Sri Lanka. BMC Med Educ 2013;13:164.

36. Shiels L, Majmundar P, Zywot A, Sobotka J, Lau CS, Jalonen TO. Medical student attitudes and educational interventions to prevent neurophobia: a longitudinal study. BMC Med Educ 2017;17:225.

37. Pakpoor J, Handel AE, Disanto G, Davenport RJ, Giovannoni G, Ramagopalan SV, et al. National survey of UK medical students on the perception of neurology. BMC Med Educ 2014;14:225.

38. Haring CM, Cools BM, van der Meer JW, Postma CT. Student performance of the general physical examination in internal medicine: an observational study. BMC Med Educ 2014;14:73.

39. George KL, Quatrara B. Interprofessional simulations promote knowledge retention and enhance perceptions of teamwork skills in a surgical-trauma-burn intensive care unit setting. Dimens Crit Care Nurs 2018;37:144-55.

40. Lerner DP, Kim J, Izzy S. Neurocritical care education during residency: opinions (NEURON) study. Neurocrit Care 2017; 26:115-8.

41. AlRomi N. Human factors in the design of medical simulation tools. Procedia Manuf 2015;3:288-92.

42. Oliveira LM, Figueiredo EG. Simulation training methods in neurological surgery. Asian J Neurosurg 2019;14:364-70.

43. Coban E, Mutluay B, Sen A, Keskek A, Atakl D, Soysal A. Characteristics, diagnosis and outcome of patients referred to a specialized neurology emergency clinic: prospective observational study. Ann Saudi Med 2016;36:51-6.

44. World Health Organization. The top 10 causes of death [Internet]. Geneva: World Health Organization; 2020 [cited 2021 May 31]. Available from: www.who.int/news-room/fact-sheets/detail/the-top-10-causes-of-death.

45. Mathers C, Stevens G, Hogan D, Mahanani WR, Ho J. Global and regional causes of death: patterns and trends, 2000-15. In: Jamison DT, Gelband H, Horton S, Jha P, Laxminarayan R, Mock CN, editors. Disease control priorities: improving health and reducing poverty. 3rd ed. Washington, DC: the Internation- al Bank for Reconstruction and Development/The World Bank; 2017.

46. Silva GS, Maldonado NJ, Mejia-Mantilla JH, Ortega-Gutierrez S, Claassen J, Varelas P, et al. Neuroemergencies in South America: how to fill in the gaps? Neurocrit Care 2019;31:573-82.

47. Ermak DM, Bower DW, Wood J, Sinz EH, Kothari MJ. Incorporating simulation technology into a neurology clerkship. J Am Osteopath Assoc 2013;113:628-35.

48. Samavedam S. Simulation benefits both the teacher and the taught. Indian J Crit Care Med 2020;24:373-4.

49. Mikhaeil-Demo Y, BarsukJH, Culler GW, Bega D, Salzman DH, Cohen ER, et al. Use of a simulation-based mastery learning curriculum for neurology residents to improve the identification and management of status epilepticus. Epilepsy Behav 2020;111:107247.

50. Tahtali D, Bohmann F, Kurka N, Rostek P, Todorova-Rudolph A, Buchkremer M, et al. Implementation of stroke teams and simulation training shortened process times in a regional stroke network-A network-wide prospective trial. PLoS One 2017; 12:e0188231.

51. Ospel JM, Kashani N, Mayank A, Cimflova P, Heran M, Pandey $S$, et al. Impact and prevention of errors in endovascular treatment of unruptured intracranial aneurysms. Interv Neuroradiol 2020;26:575-81.

52. Jabbour P, Chalouhi N. Simulation-based neurosurgical training for the presigmoid approach with a physical model. Neurosurgery 2013;73 Suppl 1:81-4.

53. Singh H, Kalani M, Acosta-Torres S, El Ahmadieh TY, Loya J, Ganju A. History of simulation in medicine: from Resusci Annie to the Ann Myers Medical Center. Neurosurgery 2013;73 Suppl 1:9-14.

54. Neurocritical Care Society. Emergency neurological life support [Internet]. Chicago, IL: Neurocritical Care Society; 2021 [cited 2021 May 31]. Available from: https://enls.neurocriticalcare. org/courses/enls-certification.

55. Nawka MT, Spallek J, Kuhl J, Krause D, BuhkJH, Fiehler J, et al. Evaluation of a modular in vitro neurovascular procedure simulation for intracranial aneurysm embolization. J Neurointerv Surg 2020;12:214-9.

56. Wurm G, Lehner M, Tomancok B, Kleiser R, Nussbaumer K. Cerebrovascular biomodeling for aneurysm surgery: simulation-based training by means of rapid prototyping technologies. Surg Innov 2011;18:294-306.

57. Benet A, Plata-Bello J, Abla AA, Acevedo-Bolton G, Saloner D, Lawton MT. Implantation of 3D-printed patient-specific aneurysm models into cadaveric specimens: a new training paradigm to allow for improvements in cerebrovascular surgery and re- 
search. Biomed Res Int 2015;2015:939387.

58. Torres IO, De Luccia N. A simulator for training in endovascular aneurysm repair: the use of three dimensional printers. Eur J Vasc Endovasc Surg 2017;54:247-53.

59. Chen PC, Lin JC, Chiang CH, Chen YC, Chen JE, Liu WH. Engineering additive manufacturing and molding techniques to create lifelike willis' circle simulators with aneurysms for training neurosurgeons. Polymers (Basel) 2020;12:2901.

60. Murphy SJ, Werring DJ. Stroke: causes and clinical features. Medicine (Abingdon) 2020;48:561-6.

61. Lang S, Hoelter P, Birkhold AI, Schmidt M, Endres J, Strother C, et al. Quantitative and qualitative comparison of 4D-DSA with 3D-DSA using computational fluid dynamics simulations in cerebral aneurysms. AJNR Am J Neuroradiol 2019;40:1505-10.

62. Keedy A. An overview of intracranial aneurysms. Mcgill J Med 2006;9:141-6.

63. Joseph FJ, Weber S, Raabe A, Bervini D. Neurosurgical simulator for training aneurysm microsurgery-a user suitability study involving neurosurgeons and residents. Acta Neurochir (Wien) 2020;162:2313-21.

64. Ryan JR, Almefty KK, Nakaji P, Frakes DH. Cerebral aneurysm clipping surgery simulation using patient-specific $3 \mathrm{D}$ printing and silicone casting. World Neurosurg 2016;88:175-81.

65. Lobel DA, Elder JB, Schirmer CM, Bowyer MW, Rezai AR. A novel craniotomy simulator provides a validated method to enhance education in the management of traumatic brain injury. Neurosurgery 2013;73 Suppl 1:57-65.

66. Hauer T, Schneider K, Mayer D, Huschitt N, Lieber A, Willy C. Human patient simulators for training in emergency surgery : needs, status quo and potential. Unfallchirurg 2019;122:45263.

67. Musacchio MJJr, Smith AP, McNeal CA, Munoz L, Rothenberg $\mathrm{DM}$, von Roenn KA, et al. Neuro-critical care skills training using a human patient simulator. Neurocrit Care 2010;13:169-75.

68. Mehta T, Strauss S, Beland D, Fortunato G, Staff I, Lee N. Stroke simulation improves acute stroke management: a systems-based practice experience. J Grad Med Educ 2018;10:57-62.

69. Dickson RL, Sumathipala D, Reeves J. Stop StrokeC acute care coordination medical application: a brief report on postimplementation performance at a primary stroke center. J Stroke Cerebrovasc Dis 2016;25:1275-9.

70. Manners J, Steinberg A, Shutter L. Early management of acute cerebrovascular accident. Curr Opin Crit Care 2017;23:556-60.

71. Guze PA. Using technology to meet the challenges of medical education. Trans Am Clin Climatol Assoc 2015; 126:260-70.

72. Chhetri SK. E-learning in neurology education: principles, opportunities and challenges in combating neurophobia. J Clin
Neurosci 2017;44:80-3.

73. Stienen MN, Schaller K, Cock H, Lisnic V, Regli L, Thomson S. eLearning resources to supplement postgraduate neurosurgery training. Acta Neurochir (Wien) 2017;159:325-37.

74. Fiani B, De Stefano F, Kondilis A, Covarrubias C, Reier L, Sarhadi K. Virtual reality in neurosurgery: "can you see it?"-a review of the current applications and future potential. World Neurosurg 2020;141:291-8.

75. McGrath JL, Taekman JM, Dev P, Danforth DR, Mohan D, $\mathrm{Kman} \mathrm{N}$, et al. Using virtual reality simulation environments to assess competence for emergency medicine learners. Acad Emerg Med 2018;25:186-95.

76. Sarkiss C, Rasouli J, Selman W, Bederson J. Surgical simulation and robotic surgery. In: Winn H. editor. Youmans and Winn neurological surgery. 7th ed. Philadelphia, PA: Elsevier; 2017.

77. Micieli G, Cavallini A, Santalucia P, Gensini G. Simulation in neurology. Neurol Sci 2015;36:1967-71.

78. Gaumard Scientific. NewroSim [Internet]. Miami, FL: Gaumard Scientific; 2021 [cited 2021 May 31]. Available from: https://www.gaumard.com/newrosim.

79. Kreiser K, Gehling K, Zimmer C. Simulation in angiography: experiences from 5 years teaching, training, and research. Rofo 2019;191:547-52.

80. Spiotta AM, Rasmussen PA, Masaryk TJ, Benzel EC, Schlenk R. Simulated diagnostic cerebral angiography in neurosurgical training: a pilot program. J Neurointerv Surg 2013;5:376-81.

81. Amin A, Salsamendi J, Sullivan T. High-fidelity endovascular simulation. Tech Vasc Interv Radiol 2019;22:7-13.

82. Liebig T, Holtmannspötter M, Crossley R, Lindkvist J, Henn P, Lönn L, et al. Metric-based virtual reality simulation: a paradigm shift in training for mechanical thrombectomy in acute stroke. Stroke 2018;49:e239-42.

83. Crossley R, Liebig T, Holtmannspoetter M, Lindkvist J, Henn P, Lonn $\mathrm{L}$, et al. Validation studies of virtual reality simulation performance metrics for mechanical thrombectomy in ischemic stroke. J Neurointerv Surg 2019;11:775-80.

84. Sakakushev BE, Marinov BI, Stefanova PP, Kostianev SS, Georgiou EK. Striving for better medical education: the simulation approach. Folia Med (Plovdiv) 2017;59:123-31.

85. Onan A, Simsek N, Elcin M, Turan S, Erbil B, Deniz KZ. A review of simulation-enhanced, team-based cardiopulmonary resuscitation training for undergraduate students. Nurse Educ Pract 2017;27:134-43.

86. Hocker S, Wijdicks EF, Feske SK, Drislane FW. Use of simulation in acute neurology training: Point and counterpoint. Ann Neurol 2015;78:337-42. 